\title{
Do UV LED Devices Immolate SARS-CoV2?
}

\author{
Waheeb E. Alnaser ${ }^{1 *}$ (), Amjad Z. Ghanem², Naser W. Alnaser ${ }^{3}$, Hacene Manaa1, Qasim Alaraibi², \\ Fatima Alshaikh²
}

${ }^{1}$ Department of Physics, College of Science, University of Bahrain, Sakhir, Kingdom of Bahrain

${ }^{2}$ Public Health Laboratory, Ministry of Health, Manama, Kingdom of Bahrain

${ }^{3}$ Department of Architecture and Interior Design, University of Bahrain, Sakhir, Kingdom of Bahrain

Email: ${ }^{\star}$ walnaser@uob.edu.bh

How to cite this paper: Alnaser, W.E., Ghanem, A.Z., Alnaser, N.W., Manaa, H., Alaraibi, Q. and Alshaikh, F. (2020) Do UV LED Devices Immolate SARS-CoV2? Health, 12, 1445-1456.

https://doi.org/10.4236/health.2020.1211105

Received: October 10, 2020

Accepted: November 13, 2020

Published: November 16, 2020

Copyright (C) 2020 by author(s) and Scientific Research Publishing Inc. This work is licensed under the Creative Commons Attribution International License (CC BY 4.0).

http://creativecommons.org/licenses/by/4.0/

\section{(cc) (i) Open Access}

\begin{abstract}
Some manufactures made UVC LED Strip as disinfection tool against SARS-CoV2. Therefore, three types of commercially UVC lights were used to evaluate their efficiency to warp bacteria and viruses. We tested three commercially available UV lights devices. They were put at 4 to $5 \mathrm{~cm}$ to spiked sterile Petri dishes (samples) for 10, 20,30, and 60 seconds and compared it to control (without UV light exposure). Also, the same three UV LED devices were used on Positive SARS-CoV2 swab samples (used for the Petri dishes). Serial dilutions of the cultured microbes were used for the experiment as follows: $1 / 10$ (high concertation), 1/100,1/1000,1/10,000, 1/100,000 (low concertation). All three UV LED devices (DA, DB, DC) were found to have no effects on the pathogens (Bacteria or SARS-CoV2), even to the lowest Bacteria Concentration $(1 / 100,000)$, when pathogens were exposed to UV radiation for $10,20,30$, and $60 \mathrm{sec}$ at distance a 4 to $5 \mathrm{~cm}$. One of the manufacturers of these UVC lights (DB) claims that the device is very effective in killing Bacteria and Virus immediately at a $99.93 \%$ killing rate (in $20 \mathrm{sec}$.). This observation was not noticed. False claims may lead to severe spread of SARS-CoV2 as customers may think that the DB was disinfecting, after short exposure, while truly having no effect.
\end{abstract}

\section{Keywords}

COVID-19, SARS-CoV2, Pathogens, UV Light Devices, UVC, Bahrain

\section{Introduction}

The outbreak of SARS-CoV2 (previously called COVID-19) on 30 January 2020 was declared globally as a Public Health Emergency and becomes of International Concern.

The transmission of this virus played an important role in the spread of coro- 
navirus. The public immediately thought of UV light as it is always thought to be able to destroy pathogens. This is found to be true if irradiation of this UVC is for relatively long period with power density larger than $90 \mu \mathrm{W} / \mathrm{cm}^{2}$ [1].

UVC LEDs have been found to have many applications such as a biological agent detection, optical data storage, water treatment, communications and polymer curing [2]. The UVC LED ( $260 \mathrm{~nm}$ to $270 \mathrm{~nm}$ ) was reported to be useful for disinfection. It is expected that with the improved development in UV LED technology (such as UVC tunable wavelengths) UVC LED will be the next generation disinfection products for medical uses because of their ability to deliver UV lights with specific wavelengths [3].

Therefore, currently, several manufactures claim that their UVC light sources can efficiently kill bacteria (sterilizing). For example, Feton Light [4] claimed that, as an air purifier, UVC light sources are becoming a popular product. Particularly, in the field of HVAC (Heating, Ventilating, and Air Conditioning), UVC light sources have shown a strong ability to eliminate viruses and bacteria.

The UVC LED companies use UVC LED Strip \& photocatalyst to disinfect air. Their system eliminates virus/bacterial/VOCs/animals smelling immediately at a 99.93\% killing rate. Their UV system, composed of UVC LED Strip and $\mathrm{TiO}_{2}$ filter, is shown in (Figure 1).

With the widespread of the coronavirus pandemic, some commercial companies made use of germicidal UV radiation technology (UVC), which was successful for many years. Since early March 2020, there has been an upsurge interest in this technology. Research funding has been granted to many academic institutions around the world to focus on this old technique that can eliminate viruses and bacteria with the help of ultraviolet light [5].

Far Ultraviolet radiation (UVC) from the sun, which is among other UV (UVA and UVB), is filtered out by the ozone molecules in the atmosphere before it can reach Earth's surface. Although it will kill germs and viruses (due to its high-energy; wavelength from $207 \mathrm{~nm}$ to $222 \mathrm{~nm}$ ), it may also cause skin cancer, destroy our DNA and damage the cornea of our eyes [5]. On one hand, UV technology has a great potential to kill pathogens but, on the other hand, it can cause serious and permanent damage on human tissues. Due to the lockdown, the spread of SARS-CoV2, warning raised by WHO (to clean hands, surfaces, shopping bags, opening envelopes and delivery packages public) companies find it more practical to use UVC for sanitizing, especially, hospitals which had been using it for years to disinfect surgical uniforms. In the present circumstances, this technology can be applied in different places such as schools, office buildings, and restaurants to disinfect them from coronavirus before being open again. Another recent example is UV Angel, a pathogen control company, which has successfully introduced two new products to the market. These products have attracted people from different horizons, and interestingly from markets outside the healthcare world [5]. Among companies' UVC light applications are sanitizers, which are popping up as potential coronavirus killer, either on our hands or on the electronic devices such as the smartphones [6]. Buonanno et al. 


\section{How it works}

\section{Feton UVC Sterilizing Process}

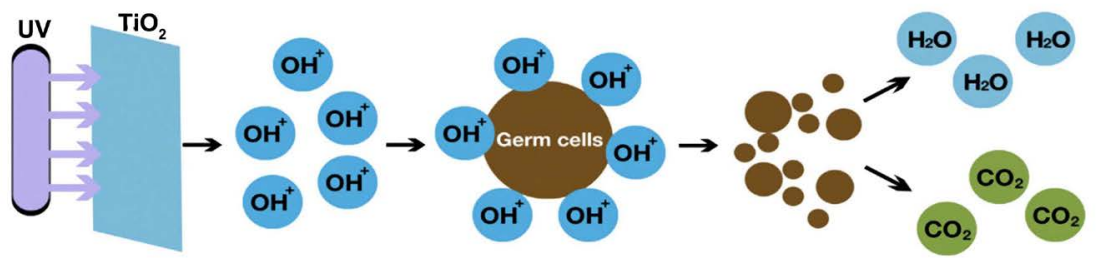

\section{Double Sterilizing Process:}

\section{1. $\mathrm{TiO}_{2}$ was irradiated by Uv LED Strip (UVA+UVC)}

2. Under Photocatalyst, strong oxidizing agent $\mathrm{OH}+$ is produced

3. $\mathrm{OH}+$ start to surround and destroy germ cells

4. Harmful substances \& allergens are disintegrated into $\mathrm{H}_{2} \mathrm{O} \& \mathrm{CO}_{2}$

5. For virus not killed by $\mathrm{TiO}_{2}, \mathrm{UV}-\mathrm{C}$ can offer supplementary function.

\section{Photocatalytic Activity}

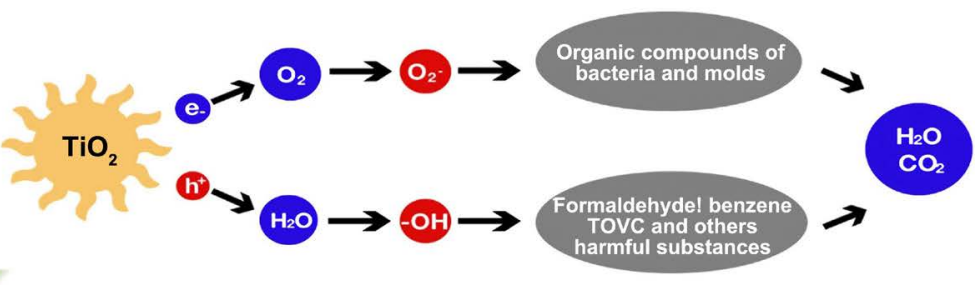

Figure 1. Advertisement of Feton technology in killing pathogens using composed of UV LED Strip and $\mathrm{TiO}_{2}$ filter [4].

[7] reported that UV light radiation at wavelength $254 \mathrm{~nm}$, has shown a certain efficiency as a virus killer, but, unfortunately, it can also constitute a health hazard to human skin and eyes. However, far UVC light with a wavelength ranging from 207 to $222 \mathrm{~nm}$ has been found to be an efficient pathogen killer, without any unwanted side effects on human eyes and skin. Moreover, it was claimed [8] [9] [10] that far-UVC radiation (wavelength $222 \mathrm{~nm}$ ) can eliminate airborne influenza virus with a high efficiency. Buonanno et al. [7] reported that a relatively low dose, such as 1.2 and $1.7 \mathrm{~mJ} / \mathrm{cm}^{2}$ (about $4 \mathrm{~mW} / \mathrm{m}^{2}$ ) could inactivate up to $99.9 \%$ of aerosolized coronavirus $229 \mathrm{E}$ and OC43, respectively. They also reported that for a distance between the UVC source and the sample of $22 \mathrm{~cm}$, at a given a period of 20 seconds, the needed total UVC exposure to kill a SARS-CoV2 was only about $2 \mathrm{~mJ} / \mathrm{cm}^{2}\left(\sim 6 \mathrm{~mW} / \mathrm{m}^{2}\right)$ [7]. Ponnaiya et al. [11] have shown that far-UVC light (wavelength $207 \mathrm{~nm}$ to $222 \mathrm{~nm}$ ) is a very 
efficient killer to bacteria without any damage to the human tissues. They insisted on the important appropriate optical filter to be added to the UVC source in order to block all radiations with wavelengths longer than $230 \mathrm{~nm}$, which may be harmful to human tissues and eyes. Browsing Amazon website [12] leads to plentiful UVC LED lamp devices such as sanitizers. Their prices are very affordable (range from US $\$ 60$ to 100) and each product has a list of positive testimony, which may encourage and attract people to purchase.

A company representative approached the University of Bahrain (UoB) to market a UVC device (DB), in June 2020; the peak month of the infected cases by SARS-CoV2 in Bahrain. It was claimed that this device would offer a rapid cleanup of objects from viruses and bacteria, i.e. just by scanning the object for $15 \mathrm{sec}$ to $20 \mathrm{sec}$ (Figure 1). The manual states that it is enough to sweep the UV disinfection device (UVC LED stick) for 5 to 10 seconds, at a distance few inches away from the surface of the object. The energetic UVC emitted from the LED lamp (wavelength $270 \mathrm{~nm}$ to $280 \mathrm{~nm}$ ) is capable to warp the pathogens since it has high antibacterial rate that reaches $99.99 \%$ (Figure 2). The evidence of this claim, according to the company, is available on the leaflet included in the device (Figure 3). Therefore, we decided to study the efficiency of UVC lights in immolate pathogens, especially SARS-CoV2. We had chosen another two devices (DA and DC) out of curiosity; the manufacturer of these two devices never claims that it kills pathogens.

This study was designed to investigate the effect of different UVC lights intensity

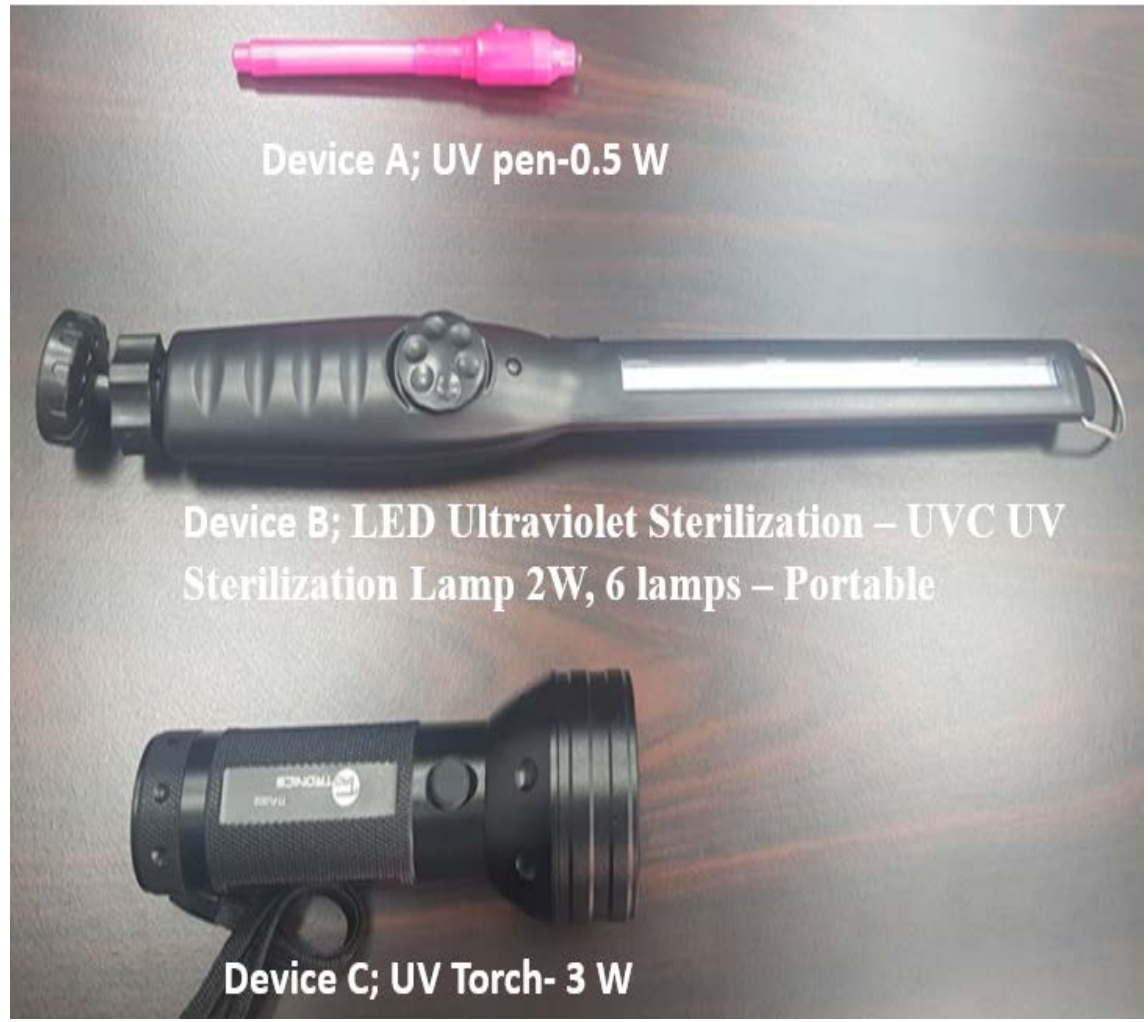

Figure 2. Three UV light tested for their ability to kill Bacteria or Viruses. 

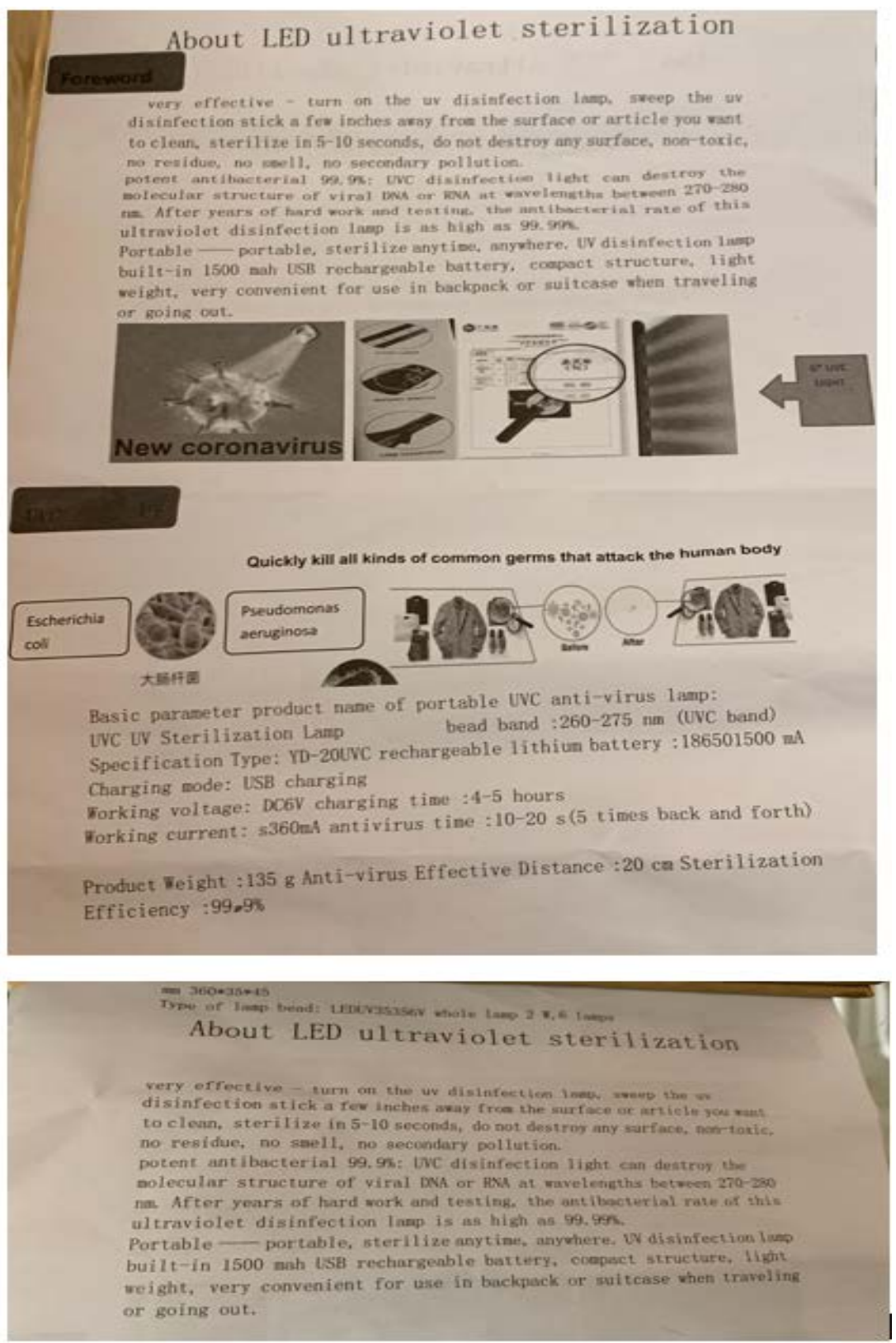

Figure 3. Instruction on how to use DB: LED Ultraviolet Sterilization, UVC UV Sterilization Lamp 2W, 6 lamps, Portable.

on the growth of four different types of microbes (Staph aureus, E. coli, Aspergillus Flavous and SARS-CoV2) with different variables (exposure time and microbial load/concentration.).

\section{Methodology}

\subsection{Method for Bacterial and Fungal Test}

1) Certain types of microbes; Staph aureus (ATCC No. 43300), E. coli (ATCC No. 35218), and Moulds (ATCC No. Aspergillus Flavous 204304) from microbiology department in public health laboratory- $\mathrm{MOH}$, have been inoculated in Buffer 
Peptone Water BPW and kept @ $37^{\circ} \mathrm{C}$ for 18 - $24 \mathrm{hr}$ (overnight).

2) Serial dilutions of the cultured microbes from step 1 have been made; $1 / 10$, $1 / 100,1 / 1000,1 / 10,000 \& 1 / 100,000$ and dilution $1 / 100,000$ areee used for the experiment.

3) Swabs from both concentrated and diluted bacterial and fungal culture were used to inoculated Nutrient agar and OGYA agar respectively.

4) One set of the inoculated culture media was at control without exposure to UVC light and the other used as a Test set with exposure to UVC light.

5) Each of the dilution culture of the Test set was exposed to UVC light from the instrument on timely intervals of $10 \mathrm{sec}, 20 \mathrm{sec}, 30 \mathrm{sec}, 60 \mathrm{sec}$ with distance of 4 to $5 \mathrm{~cm}$ above the plate.

6) All inoculated Control and Test samples incubated overnight @ $37^{\circ} \mathrm{C}$.

\subsection{Method for Bacterial \& COVID19 Test}

1) Known SARS-CoV2 positive sample (from Public Health lab, communicable disease unit) with cut of titer CT of 21 used to inoculate sterile plate for the trial.

2) Sterile swab used to spread for control without exposure to UV light and five other plates used for testing with UV light.

3) Each of the five inoculated plates with bacterial growth and SARS-CoV2 was exposed to UVC lamp on timely intervals of $10 \mathrm{sec}, 20 \mathrm{sec}, 30 \mathrm{sec}, 60 \mathrm{sec}$ with distance of $4-5 \mathrm{~cm}$ height from the plate and Swabs were taken directly from the UV time exposure of each control and test samples.

4) The control samples were incubated @ $37^{\circ} \mathrm{C}$ without exposure to UV light, while the test samples were exposed first to UVC light from the device for both of Bacterial as well as for SARS-CoV2.

\section{Result \& Discussion}

Figure 4 shows the Serial dilutions of the cultured microbes and different dilution $(1 / 10,1 / 100,1 / 1000,1 / 10,000$ and $1 / 100,000)$ exposed to different UV light dose $(10,20$ and $30 \mathrm{sec})$ at a distance from $4-5 \mathrm{~cm}$. The results show, clearly, the ineffectiveness of UV light on the Bacteria.

Figure 5 shows five inoculated plates with bacterial growth and SARS-CoV2 exposed to different UVC light dose (10,20 and 30 seconds) at a distance from 4 $-5 \mathrm{~cm}$. The results show ineffectiveness of UVC light on SARS-CoV2.

Table 1 shows the result of microbial culture (Staph aureus, E. coli) with and without exposure to UV light when using DA. The manufacturer of this device never claims it is suitable for disinfection from pathogens. The emitted UVC was not efficient even with the lowest bacteria concentration.

Table 2 shows the result of microbial culture (Staph aureus, E. coli and Moulds) with and without exposure to UVC light using DB (called portable UV disinfection stick). The emitted UVC also shows no effect even with the lowest bacteria concentration. 


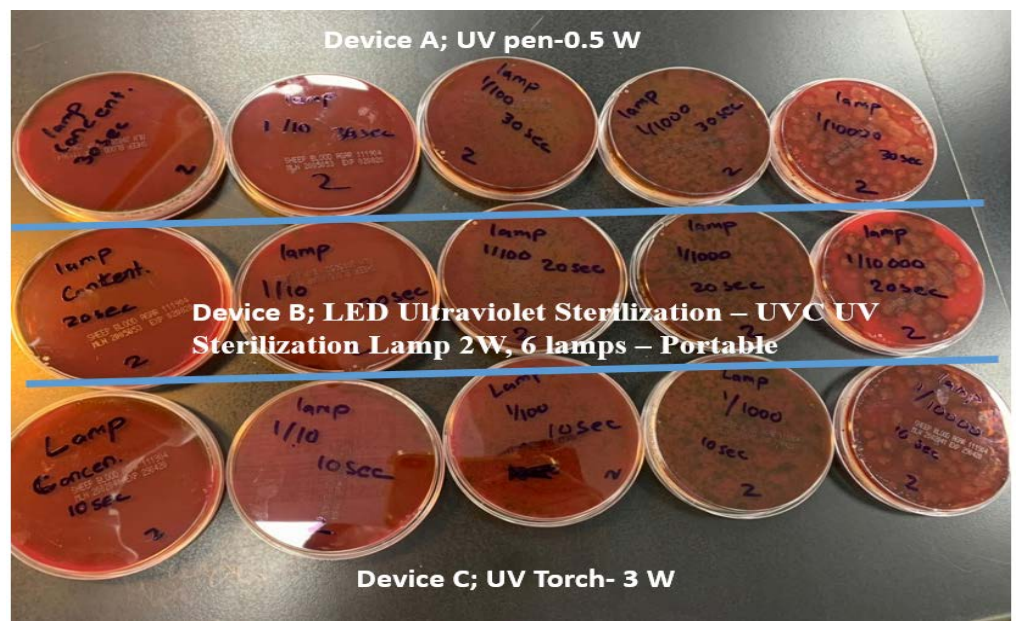

Figure 4. The growth of cultured microbes and different dilution $(1 / 10,1 / 100,1 / 1000$, $1 / 10,000 \& 1 / 100,000$ and dilution $1 / 100,000$ ) exposed to different UV light dose. The results show ineffectiveness of UV on the Bacteria.

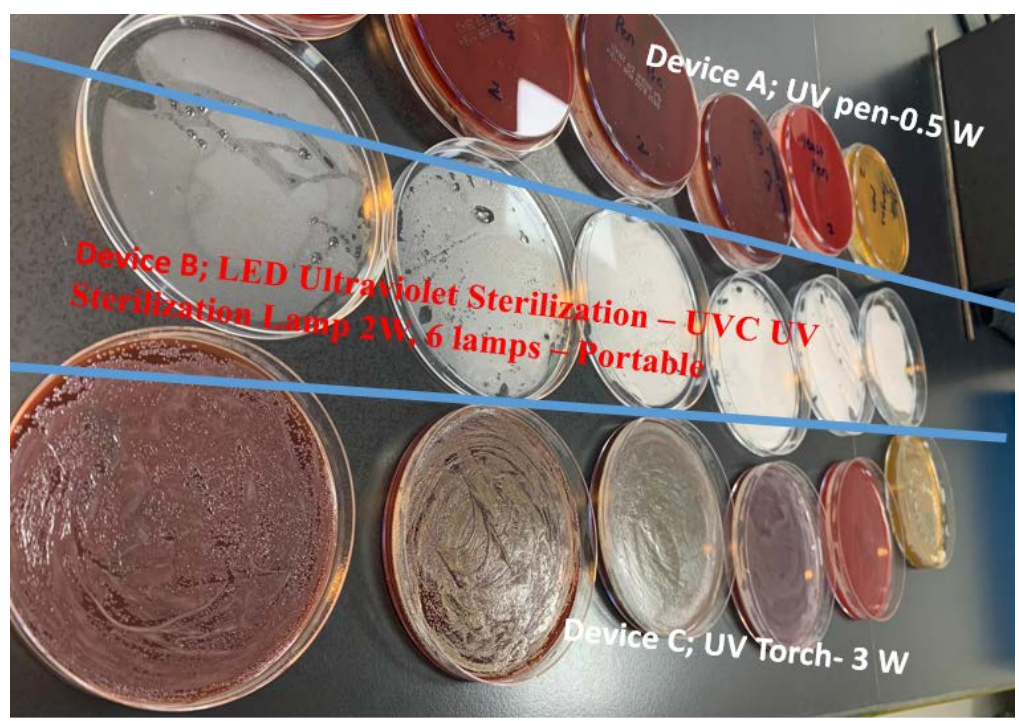

Figure 5. Five inoculated plates with bacterial growth and COVID19 exposed to different UV light dose. The results show ineffectiveness of UV on COVID-19.

Table 1. Result of microbial culture (Staph aureus, E. coli) with and without exposure to UV light when using DA.

\begin{tabular}{ccc}
\hline \multirow{2}{*}{ Condition } & Time Intervals & Dilution \\
\cline { 3 - 3 } & & $1 / 10,000$ \\
\hline \multirow{2}{*}{ Without UV (Control) } & $10 \mathrm{sec}$ & High Growth \\
& $20 \mathrm{sec}$ & High Growth \\
& $30 \mathrm{sec}$ & High Growth \\
$60 \mathrm{sec}$ & High Growth \\
Exposure to UV & $10 \mathrm{sec}$ & High Growth \\
& $20 \mathrm{sec}$ & High Growth \\
& $30 \mathrm{sec}$ & High Growth \\
& $60 \mathrm{sec}$ & High Growth \\
\hline
\end{tabular}


Table 2. Result of microbial culture (Staph aureus, E. coli and Moulds) with and without exposure to UV light using DB (called portable UVC disinfection stick).

\begin{tabular}{ccc}
\hline Condition & Time Intervals & Dilution \\
\cline { 2 - 3 } & $10 \mathrm{sec}$ & $\mathbf{1 / 1 0 , 0 0 0}$ \\
\hline Without UVC (Control) & $20 \mathrm{sec}$ & High Growth \\
& $30 \mathrm{sec}$ & High Growth \\
& $60 \mathrm{sec}$ & High Growth \\
$10 \mathrm{sec}$ & High Growth \\
Exposure to UVC & $20 \mathrm{sec}$ & High Growth \\
& $30 \mathrm{sec}$ & High Growth \\
& $60 \mathrm{sec}$ & High Growth \\
\hline
\end{tabular}

Table 3 shows the results of microbial culture (Staph aureus, E. coli) with and without exposure to UV light using handheld UV torch device (DC). The manufacturer never claims its efficiency for disinfection. Akin to the previous cases, the emitted UV also shows no effect even with the lowest bacteria concentration.

Table 4 summarizes the result of exposure to UV light dose for various time (from 10 to 30 seconds) at a distant of $4-5 \mathrm{~cm}$. The microbial cultures (Staph aureus, Pseudomonas aeruginosa, E. coli, Yeast, Bacillus cereus, and Moulds) were found to be unaffected by UVC light exposure from the three devices.

On testing the effect of UVC light on SARS-CoV2, similar results were obtained - as expected. None of the three devices had shown any trace of an effect on pathogens. The results are shown in Table 5.

Many reported works [13] [14] [15] [16] [17] had reported the advantage in UVC light for partial disinfecting but only at much larger exposure cycle and not at low dose (low power and exposure time $-20 \mathrm{sec}$ ). Rutala et al. [18] reported exposure time of $5 \mathrm{~min}$ to achieve an overall 3.56- $\log 10$ reduction for MRSA and when patient's room walls were treated with UVC reflective wall coating, the Optimum UVC achieved an overall 4.5- $\log 10$ reduction in 5 minutes.

Pavia et al. [19] reported that UVC implementation was associated with a $44 \%$ reduction in viral infection incidence among pediatric patients in a long-term care facility when included as an adjunct to standard cleaning protocols over a 12 -month period. There results suggest that UVC technology is a potentially important component of eliminating the environment as a source of viral infections when used as long-term. Furthermore, the work of Malhotra et al. [20] in using UVC for pathogenicity of health care providers' mobile phones was conducted before and after the UVC device's 30-sec disinfecting cycle, at the beginning and end of a 12-hour shift.

It was noted that purchasers of such UVC devices as well as interested in acquiring it are of age 40 to 60 years. This is nearly the most common age that was reported to have caught SARS-CoV2 in the early stages of the spread of the disease 
Table 3. Result of microbial culture (Staph aureus, E. coli) with and without exposure to UV light using handheld UV torch device (DC). The manufacturer never claim it is for disinfection.

\begin{tabular}{ccc}
\hline \multirow{2}{*}{ Condition } & Time Intervals & Dilution \\
\cline { 2 - 3 } & $10 \mathrm{sec}$ & $\mathbf{1 / 1 0 , 0 0 0}$ \\
\hline \multirow{2}{*}{ Without UV (Control) } & $20 \mathrm{sec}$ & High Growth \\
& $30 \mathrm{sec}$ & High Growth \\
$60 \mathrm{sec}$ & High Growth \\
$10 \mathrm{sec}$ & High Growth \\
$20 \mathrm{sec}$ & High Growth \\
Exposure to UV & $30 \mathrm{sec}$ & High Growth \\
& $60 \mathrm{sec}$ & High Growth \\
\hline
\end{tabular}

Table 4. Results of the microbial cultures (Staph aureus, Pseudomonas aeruginosa, E. coli, Yeast, Bacillus cereus, and Moulds) after exposed to UVC lights (DA, DB and DC) at different intervals.

\begin{tabular}{|c|c|c|c|c|c|c|}
\hline \multirow{2}{*}{ Condition } & \multirow{2}{*}{$\begin{array}{c}\text { Time } \\
\text { Intervals }\end{array}$} & \multicolumn{5}{|c|}{ Dilution } \\
\hline & & Concentrated & $1 / 10$ & $1 / 100$ & $1 / 100$ & $1 / 10000$ \\
\hline \multirow{3}{*}{$\begin{array}{c}\text { Without } \\
\text { UVC }\end{array}$} & $10 \mathrm{sec}$ & High Growth & High Growth & High Growth & High Growth & High Growth \\
\hline & $20 \mathrm{sec}$ & High Growth & High Growth & High Growth & High Growth & High Growth \\
\hline & $30 \mathrm{sec}$ & High Growth & High Growth & High Growth & High Growth & High Growth \\
\hline \multirow{3}{*}{$\begin{array}{c}\text { Exposure to } \\
\text { UVC }\end{array}$} & $10 \mathrm{sec}$ & High Growth & High Growth & High Growth & High Growth & High Growth \\
\hline & $20 \mathrm{sec}$ & High Growth & High Growth & High Growth & High Growth & High Growth \\
\hline & $30 \mathrm{sec}$ & High Growth & High Growth & High Growth & High Growth & High Growth \\
\hline
\end{tabular}

Table 5. Result of SARS-CoV2 positive sample swab with and without exposure to different UVC lights.

\begin{tabular}{ccc}
\hline Condition & Time Intervals & Result \\
\hline & $10 \mathrm{sec}$ & SARS-CoV2 Detected \\
Without UVC & $20 \mathrm{sec}$ & SARS-CoV2 Detected \\
& $30 \mathrm{sec}$ & SARS-CoV2 Detected \\
$60 \mathrm{sec}$ & SARS-CoV2 Detected \\
& $10 \mathrm{sec}$ & SARS-CoV2 Detected \\
& $20 \mathrm{sec}$ & SARS-CoV2 Detected \\
Exposure to UVC & $30 \mathrm{sec}$ & SARS-CoV2 Detected \\
& $60 \mathrm{sec}$ & SARS-CoV2 Detected \\
\hline
\end{tabular}

[21] [22]. Unfortunately, the claims of such devices are vague, i.e. they are unable to immolate SARS-CoV2. 
As long the virus exists and is spreading fast and overwhelmed health systems causing widespread social and economic disruption people will vulnerable to purchase devices claiming to kill or immolate SARS-CoV2.

This pandemic will alter the world forever and new medical product will be in the market - whether genuine or fake! There will be increased confidence in technology and nations will invest more in public health. According to Tabish [23] an economic slowdown, severe recession, plummeting revenue, increased expenditure, and mental health issues could be the emerging challenges.

Investing in public health, preparedness, and relying on science will bring a better future. It is hoped that standardized protocol for testing UVC against SARS-CoV2 comes soon.

\section{Conclusions}

All the three UV devices (DA, DB and DC) have no effects on reducing the microbial growth with the dilution made at exposure time intervals. Therefore, it can be concluded that DB is not achieving its marketing claim of warping bacteria and viruses effectively and promptly. False claims may lead to severe spread of SARS-CoV2 as customers may think that their hands or objects have been sterilized and disinfected after being exposed to UV light devices, while, such devices seem to have no effects. It is worth mentioning that there is no clear protocol to be followed to test the efficiency of UVC light on SARS-CoV2.

Based on previous work [7], the UV dose provided by these three devices is believed to be much less than $1 \mu \mathrm{W} / \mathrm{cm}^{2}$. Other standardized protocols should be followed for testing the effect of UVC light on SARS-CoV2 using further UVC treatment time intervals.

\section{Acknowledgements}

The authors thank the University of Bahrain (UoB) and the Ministry of Health, Kingdom of Bahrain, for their moral and logistic support to conduct this study. The authors are also grateful to Zahra J. AlAAli for her technical assistance. Thanks, are extended to Dr. Ghada Ahmed, UoB, for editing this paper.

\section{Conflicts of Interest}

The authors declare no conflicts of interest regarding the publication of this paper.

\section{References}

[1] Kalyani, V.L., Mathur, P., Makwana, N. and Singhal, N. (2020) Study on Coronavirus (COVID-19) and How UVC Light Helps to Destroy It and Its Applications. Journal of Management Engineering and Information Technology, 7, 2394-8124. https://www.researchgate.net/publication/342735132 Study on Coronavirus COV ID-19 and how UVC Light helps to Destroy it and its Applications

[2] Kahn, K. (2020) How a UVC LED Works. https://www.klaran.com/how-a-uvc-led-works 
[3] Chen, Y.N. (2020) How UV LEDs Might Help to Diminish Coronavirus. https://www.ledinside.com/news/2020/2/uvled coronavirus

[4] Feton Light (2020) UV Light LED System Mercury Free Version for Mini-Splits HVAC Units Indoor Air-Conditioning. https://www.fetonlight.com/Led-lamps/UVC-solution-for-mini-splits?gclid=Cj0KC QjwpZT5BRCdARIsAGEX0zluEMhM4q2YFN9jtMzRV17tcQYnk7dgLx5d6eL94M D SJRrMcBu3BMaAmKHEALw wcB

[5] Kalter, L. (2020) Coronavirus Puts UV in the Disinfectant Spotlight. https://www.webmd.com/lung/news/20200519/coronavirus-puts-uv-in-the-disinfec tant-spotlight

[6] Capritto, A. (2020) Using UV Light to Kill Coronavirus: The Benefits and Risks. https://www.cnet.com/health/can-uv-light-protect-you-from-covid-19/

[7] Buonanno, M., Welch, D., Shuryak, I. and Brenner, D.J. (2020) Far-UVC Light (222 $\mathrm{nm})$ Efficiently and Safely Inactivates Airborne Human Coronaviruses. Scientific Reports, 10, Article No. 10285. https://doi.org/10.1038/s41598-020-67211-2

[8] Buonanno, M., Randers-Pehrson, G., Bigelow, A.W., Trivedi, S., Lowy, F.D., Spotnitz, H.M., Hammer, S.M. and Brenner, D.J. (2013) 207-nm UV Light-A Promising Tool For Safe Low-Cost Reduction Of Surgical Site Infections. I: In Vitro Studies. PloS ONE, 8, e76968. https://doi.org/10.1371/journal.pone.0076968

[9] Buonanno, M., (2016) 207-nm UV Light-A Promising Tool For Safe Low-Cost Reduction of Surgical Site Infections. II: In-Vivo Safety Studies. PLoS ONE, 11, e0138418. https://doi.org/10.1371/journal.pone.0138418

[10] Buonanno, M., Stanislauskas, M., Ponnaiya, B., Bigelow, A.W., Randers-Pehrson, G., Xu, Y., Shuryak, I., Smilenov, L., Owens, D. and Brenner, D.J. (2017) Germicidal Efficacy and Mammalian Skin Safety of 222-nm UV Light. Radiation Research, 187, 483-491. https://doi.org/10.1667/RR0010CC.1

[11] Ponnaiya, B., Buonanno, M., Welch, D., Shuryak, I., Randers-Pehrson, G. and Brenner, D.J. (2013) Far-UVC Light Prevents MRSA Infection of Superficial Wounds In Vivo. PLoS ONE, 13, e0192053. https://doi.org/10.1371/journal.pone.0192053

[12] Amazon.com (2020). https://www.amazon.com/slp/uv-sanitizer/ay9hn5w9tps4fgf

[13] Anderson, D.J., Chen, L.F., Weber, D.J., Moehring, R.W., Lewis, S.S., Triplett, P.F., Blocker, M., Becherer, P., Schwab, J.C., Knelson, L.P., Lokhnygina, Y., Rutala, W.A., Kanamori, H., Gergen, M.F., Sexton, D.J. and CDC Prevention Epicenters Program (2017) Enhanced Terminal Room Disinfection and Acquisition and Infection Caused By Multidrug-Resistant Organisms and Clostridium Difficile. Lancet, 389, 805-814. https://doi.org/10.1016/S0140-6736(16)31588-4 http://linkinghub.elsevier.com/retrieve/pii/S0140673616315884

[14] Haas, J.P., Menz, J., Dusza, S. and Montecalvo, M.A. (2014) Implementation and Impact of Ultraviolet Environmental Disinfection in an Acute Care Setting. American Journal of Infection Control, 42, 586-590.

https://doi.org/10.1016/j.ajic.2013.12.013

[15] Nagaraja, A., Visintainer, P., Haas, J.P., Menz, J., Wormser, G.P. and Montecalvo, M.A. (2015) Clostridium Difficile Infections before and during Use of Ultraviolet Disinfection. American Journal of Infection Control, 43, 940-945. https://doi.org/10.1016/j.ajic.2015.05.003

[16] Pegues, D.A., Han, J., Gilmar, C., McDonnell, B. and Gaynes S. (2017) Impact of Ultraviolet Germicidal Irradiation for No-Touch Terminal Room Disinfection on Clostridium Difficile Infection Incidence among Hematology-Oncology Patients. 
Infection Control \& Hospital Epidemiology, 38, 39-44.

https://doi.org/10.1017/ice.2016.222

[17] Rock, C., Curless, M.S., Nowakowski, E., Ross, T., Carson, K.A., Trexler, P., Carrol, K. and Maragakis, L.L. (2016) UV-C Light Disinfection of Carbapenem-Resistant Enterobacteriaceae from High-Touch Surfaces in a Patient Room and Bathroom. Infection Control \& Hospital Epidemiology, 37, 996-997.

https://doi.org/10.1017/ice.2016.111

[18] Rutala, W.A., Gergen, M.F., Tande, B.M. and Weber D.J. (2014) Room Decontamination Using an Ultraviolet-C Device with Short Ultraviolet Exposure Time. Infection Control \& Hospital Epidemiology, 35, 1070-1072.

https://doi.org/10.1086/677149

[19] Pavia, M., Simpser, E., Becker, M., Mainquist, W.K. and Velez, K.A. (2018) The Effect of Ultraviolet-C Technology on Viral Infection Incidence in a Pediatric Long-Term Care Facility. American Journal of Infection Control, 46, 720-722. https://doi.org/10.1016/j.ajic.2018.01.014

[20] Malhotra, S., Wlodarczyk, J., Kuo, C., Ngo, C., Glucoft, M., Sumulong, I., Smit, M.A. and Bender, J.M. (2020) Shining a Light on the Pathogenicity of Health Care Providers' Mobile Phones: Use of a Novel Ultraviolet-C Wave Disinfection Device. American Journal of Infection Control, 48, 1370-1374.

https://doi.org/10.1016/j.ajic.2020.05.040

[21] Alsofayan, M.Y., Althunayyan, S.M., Khan, A.A, Hakawi, A.M. and Assiri, A.M. (2020) Clinical Characteristics of COVID-19 in Saudi Arabia: A National Retrospective Study. Journal of Infection and Public Health, 13, 920-925. https://doi.org/10.1016/j.jiph.2020.05.026

[22] Harapan, H., Itoh, N., Yufika, A., Winardi, Keam, K., Te, H., Megawati, D., Hayati, Z., Wagner, W.L. and Mudatsir, W. (2020) Coronavirus Disease 2019 (COVID-19): A Literature Review. Journal of Infection and Public Health, 13, 667-673. https://doi.org/10.1016/j.jiph.2020.03.019

[23] Tabish, S. (2020) Tackling SARS-CoV-2 Pandemic: The Way Forward. Health, 12, 1202-1216. https://doi.org/10.4236/health.2020.129088 